Brit. J. Psychiat. (1975), 127, 564-74

\title{
Deliberate Self-Harm: Clinical and Socio-Economic Characteristics of 368 Patients
}

\author{
By H. GETHIN MORGAN, CHRISTOPHER J. BURNS-COX, \\ HELEN POCOCK and SUSAN POTTLE
}

\begin{abstract}
Summary. In this study 368 patients were interviewed after they had attended the Bristol Royal Infirmary Accident and Emergency Department following a non-fatal act of deliberate self-harm. There were twice as many women (247) as men (121), and two thirds of the patients were in the 15-35 age group. Ninetyfive per cent had taken a drug overdose, most commonly one or more of the tranquillizers, antidepressants, hypnotics or analgesics. Seventy-eight per cent had taken drugs prescribed by a doctor. Half the patients mentioned interpersonal conflict as a major precipitating factor in the episode. A psychiatric diagnosis was completed for all admitted patients, of whom 52 per cent were considered to be suffering from neurotic depression, 29 per cent from personality disorder, 12 per cent from functional psychosis and 10 per cent from alcohol addiction. Almost half had deliberately harmed themselves on a previous occasion. The series showed a greater than average incidence of unemployment, overcrowded living conditions, divorce and antisocial behaviour. The implications of these findings for the clinical management and prevention of non-fatal deliberate self-harm are discussed.
\end{abstract}

\section{INTRODUCTION}

Deliberate self-harm has become a major health problem, which has increased in size during the last decade at a rate of about ro per cent per annum (Aitken et al., 1969; Alderson, 1974). In a previous paper we showed that the incidence of self-harm in Bristol is comparable in magnitude to that in other British cities, and we emphasized the very high concentration of the problem in the urban centre.

Patients who have deliberately harmed themselves have been thoroughly documented (Weissman, 1974) and it has been shown consistently that they differ in certain characteristics from those who actually kill themselves. However, we know relatively little about the best methods of treatment, let alone ways in which such behaviour may be prevented. The problem continues to increase in size, and we need to monitor the situation regularly in order to detect possible changes in its main characteristics.
Our study set out to determine the outcome of deliberate self-harm by following up a large series of such patients who have made contact with hospital services. In this way predictions of outcome would be delineated by relating initial characteristics to subsequent progress, thereby providing guidelines for clinical management. The present paper describes our findings regarding the clinical and socioeconomic characteristics of a series of patients interviewed soon after an episode of self-harm.

\section{Method}

Deliberate self-harm was defined as a non-fatal act, whether physical injury, drug overdosage or poisoning, carried out in the knowledge that it was potentially harmful and, in the case of drug overdosage, that the amount taken was excessive. The series included all patients aged 15 years and over coming under this definition who attended the Accident and Emergency Department of the Bristol Royal Infirmary during a total period of ten months during 1972: the method of case detection has already 
BY H. GETHIN MORGAN, GHRISTOPHER J. BURNS-COX, HELEN POCOCK AND SUSAN POTTLE 565

been described (Morgan et al., 1975). Drug addicts were excluded unless there was evidence of a deliberate act of self-harm involving an amount of drug over and above the usual intake. Owing to the large numbers of patients it was necessary to exclude the months of August and December; patients who attended during this time were not significantly different in age and sex characteristics from those included in the study, and there is no reason to believe that their exclusion introduced any bias in case selection. Patients were interviewed by a member of the research team as soon as possible after self-harm, using a semi-structured questionnaire: the majority of these interviews took place in medical wards, and information from the patient was supplemented by data from hospital notes. The content of the interview ranged widely over personal, social and clinical data, selected after a pilot study over the previous year. Inter-observer reliability was assessed on a small series of twelve patients and only those items in which it was possible to achieve greater than 90 per cent agreement between raters of the same interview were retained in the definitive version of the questionnaire. Basic cross-checks were applied before computer analysis to confirm the internal consistency of the data. Supplementary information was also obtained by asking the service psychiatrists who saw the patients to specify a psychiatric diagnosis in each case, using as a guide the Glossary of Mental Disorder published by the General Register Office (1968). Additional psychiatric assessment was achieved by asking each patient to complete the Middlesex Hospital Questionnaire.

\section{Results}

A total of 470 patients fulfilling the above criteria attended the Department during the study period. Of these, the research team interviewed 368 soon after the episode of selfharm, usually within 24 hours, and it is with these patients that the present report is concerned. The remaining 102 patients were not interviewed and will be described separately; either they were not admitted (55) or they left the ward too soon to be interviewed (47). This latter group resembled the main interview series very closely.

\section{The 368 interviewed patients}

In the majority of cases ( 78 per cent) interviews took place in the medical ward to which the patient had been admitted after self-harm; the remainder were seen at home or in other hospital Departments. There were twice as many women (247) as men (121), and two thirds of the patients were in the 15-35 age group (Fig. 1). The series contained a greater than average number of single and divorced persons and fewer married and widowed (Table I).

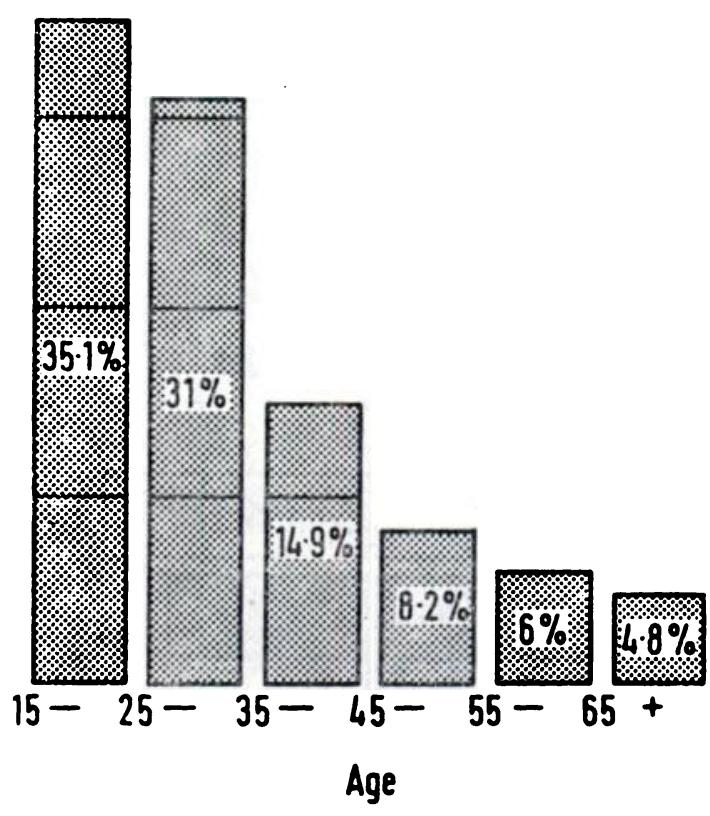

Fio. 1.

Method of self-harm (Fig. 2): Ninety-five per cent of all the episodes involved a drug overdose. Forty-nine per cent of patients used psychotropic drugs (i.e. tranquillizers, antidepressants and non-barbiturate hypnotics). Barbiturates were taken by 14 per cent and salicylates by 17 per cent. The category 'other drugs' includes a wide variety of prescribed compounds such as antibiotics, steroids, antispasmodic and hormone preparations. The wide variety of agents used meant that in some cases it was very difficult to decide the precise nature of the ingested agent.

Use of different kinds of drugs was agerelated (Fig. 3). Use of hypnotics, including barbiturates, increased with age (taken by $5^{8}$ per cent of the patients aged 55 and over). Analgesics, including salicylates, were more common among younger patients (used by 76 
566 DELIBERATE SELF-HARM: CLINICAL AND SOCIO-ECONOMIC CHARAGTERISTICS OF 368 PATIENTS

TABLE I

Civil status and social class

\begin{tabular}{|c|c|c|c|c|c|c|c|c|c|}
\hline & & & & & & \multicolumn{2}{|c|}{ Male } & \multicolumn{2}{|c|}{ Female } \\
\hline & & & & & & $\begin{array}{l}\text { Series } \\
N= \\
121(\%)\end{array}$ & $\begin{array}{c}\text { General } \\
\text { population } \\
\%\end{array}$ & $\begin{array}{l}\text { Series } \\
N= \\
247(\%)\end{array}$ & $\begin{array}{c}\text { General } \\
\text { population } \\
\%\end{array}$ \\
\hline \multicolumn{10}{|l|}{ Civil status: } \\
\hline Single & & & . & & .. & $4^{8}(40)$ & (25) & $83(34)$ & (20) \\
\hline Married (i & ding & gall & epar & & . & $62(51)$ & (70) & $132(53)$ & $(64)$ \\
\hline Widowed & .. & . & .. & .. & . & $3(2)$ & (4) & $18(7)$ & (14) \\
\hline Divorced & . & . & . & . & . & $8(7)$ & (I) & $14(6)$ & (2) \\
\hline \multicolumn{10}{|l|}{ Social class: } \\
\hline I-III & . & . & . & $\cdots$ & $\cdots$ & $68(56)$ & $(71)$ & $154(63)$ & \\
\hline IV-V & . & . & . & . & . & $53(44)$ & (29) & $93(37)$ & \\
\hline
\end{tabular}

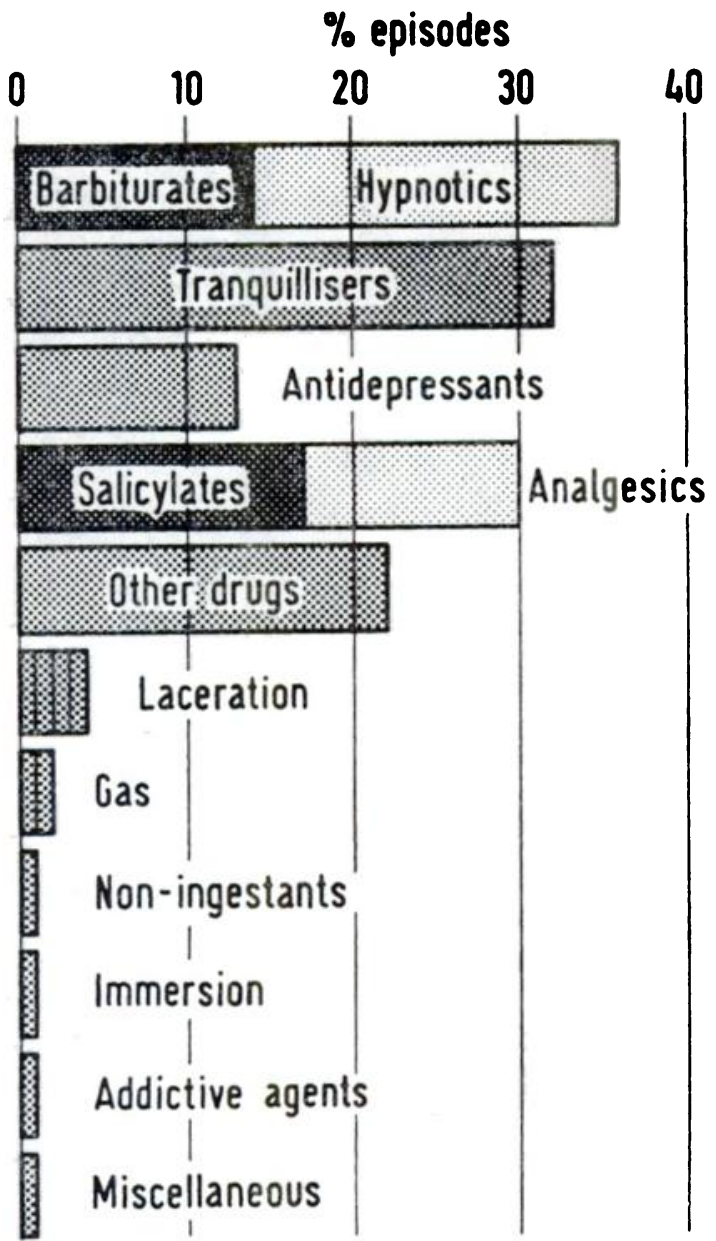

Fig. 2. per cent of patients aged $15-19)$. Tranquillizers constituted the main drug group among patients aged 20-34 years. All of these trends with age are statistically significant by the $x^{2}$ test at $\mathrm{p}<0.0 \mathrm{I}$. In contrast, the frequency with which antidepressants were used did not appear to differ with age.

Origin of drug used: Seventy-eight per cent of the patients took drugs which had been obtained by medical prescription ( 67 per cent prescribed for the patient, I I per cent for someone else). Many patients had received the prescription recently, 45 per cent in the previous month and 7 per cent within 24 hours. Twenty-five per cent used drugs which had been bought without prescription (9 per cent within 24 hours).

Circumstances of the act of self-harm and motivation: Only a minority (I 4 per cent) had actually warned others beforehand of their intention to harm themselves. However, once self-harm had occurred 44 per cent told someone about it. No precautions were taken to avoid discovery by 63 per cent, and only a very small number had actually made plans to prepare for death. Eighteen per cent left a suicide note. Half the patients had contemplated self-harm some time during the previous month, but 65 per cent said they had no definite plan at the time of the act. Twenty-seven per cent believed that death was to be expected as a consequence of their action. At the time, more males ( 46 per cent) than females (34 per cent) wanted to die (Table II), 
BY H. GETHIN MORGAN, CHRISTOPHER J. BURNS-COX, HELEN POCOGK AND SUSAN POTTLE 567

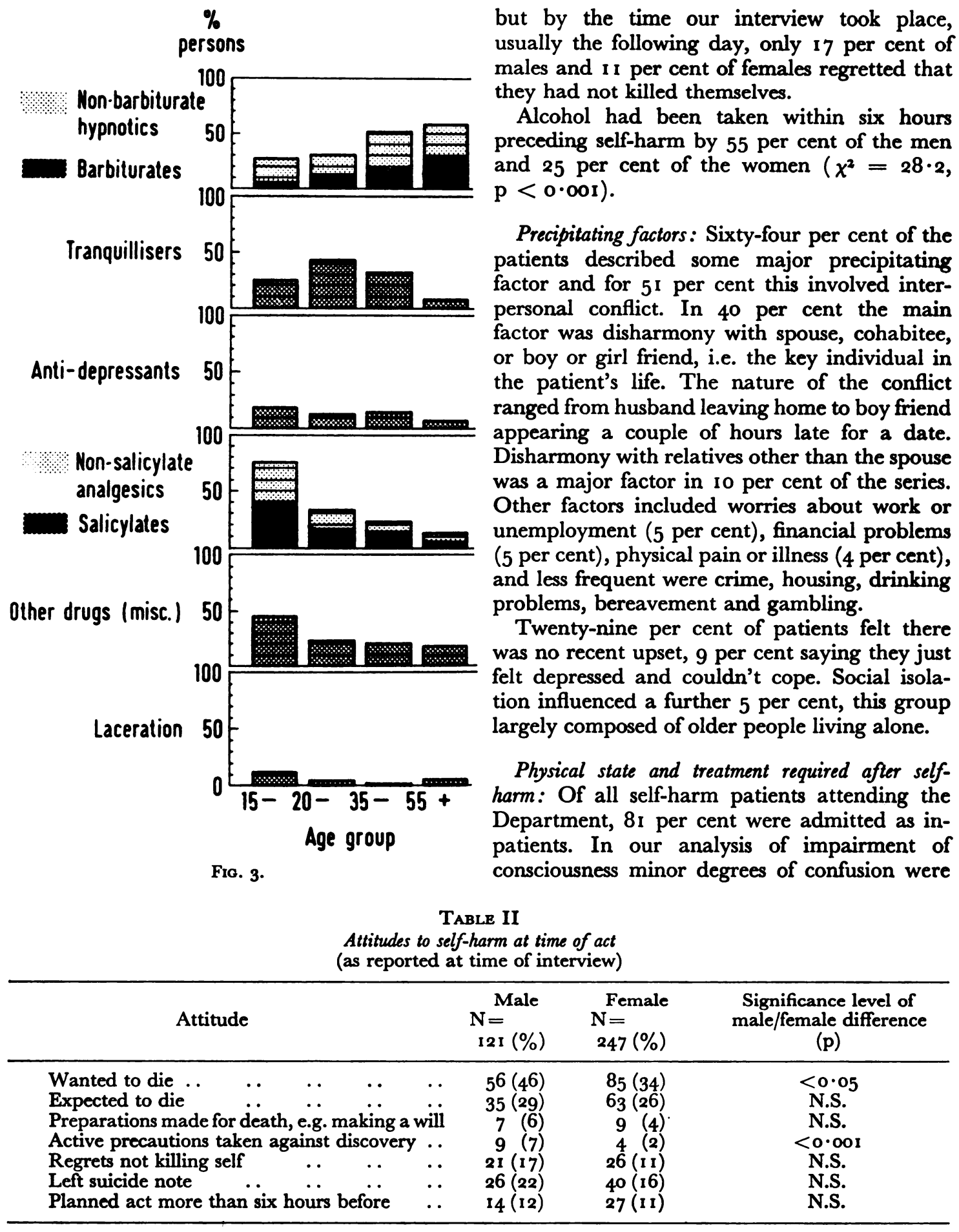


568 DELIBERATE SELF-HARM: CLINICAL AND SOCIO-BCONOMIC CHARACTERISTICS OF 368 PATIENTS

ignored, and only those instances in which the patients did not respond to verbal commands at some time were regarded as significant. More men ( 26 per cent) than women ( 15 per cent) fell into this category $\left(x^{2}=6 \cdot 2, \mathrm{p}<0 \cdot 05\right)$. Five per cent of patients were unconscious for more than 12 hours, and 4 per cent were admitted to the Intensive Care Unit. In the majority only simple nursing care was necessary, but in 21 per cent more active treatment such as intravenous infusion or use of respirator was given. Some patients (10 per cent) showed uncooperative and occasionally aggressive behaviour in the Accident Department. Fifty per cent accepted a psychiatric out-patient appointment, and 20 per cent were admitted to psychiatric wards. More males (27 per cent) than females (16 per cent) left without psychiatric follow-up $\left(x^{2}=5 \cdot 1, p<0.05\right)$. While this may seem surprising in view of the consistent tendency for the act of self-harm to appear more serious in males, both with regard to their intention to die and the incidence of loss of consciousness, the difference is probably accounted for by more males ( 14 per cent) than females (4 per cent) refusing psychiatric care $\left(x^{2}=10 \cdot 5\right.$, $\mathrm{p}<0.01)$.

Psychiatric diagnosis: It was necessary to confine this part of the study to those patients who were admitted to hospital (338), as it was impossible to categorize the remainder because of inadequate information. Formal psychiatric diagnoses were obtained from the hospital psychiatric staff for 70 per cent of the patients who had been admitted to the wards. The research psychiatrist (H.G.M.) made a diagnosis based on retrospective case note analysis in the remaining patients. In this way all patients who had been admitted were categorized (Table III).

Mental illness was judged to be absent in 10 per cent of patients. The most common diagnostic groups were reactive (neurotic) depression (52 per cent), personality disorder

TABLE III

Psychiatric diagnosis

Patients admitted to hospital

(some patients had more than one diagnosis)

\begin{tabular}{|c|c|c|c|c|c|c|c|c|c|c|}
\hline \multicolumn{4}{|l|}{ Diagnosis } & \multicolumn{3}{|c|}{$\begin{array}{c}\text { Total series } \\
\mathbf{N}=337 \quad(\%)\end{array}$} & \multicolumn{2}{|c|}{ Male } & \multicolumn{2}{|c|}{$\begin{array}{c}\text { Female } \\
\mathrm{N}=223\end{array}$} \\
\hline Mental illness absent .. & .. & .. & .. & .. & 33 & (10) & 6 & (5) & 27 & (12) \\
\hline Personality disorder $\quad$. & .. & .. & . & .. & 97 & (29) & $4^{8}$ & $(42)$ & 49 & (22) \\
\hline $\begin{array}{lll}\text { Neurosis } & . \\
\text { Neurotic (reactive) dep } \\
\text { Other } & . . & \ldots\end{array}$ & $\begin{array}{l}\text {. } \\
\text { ression } \\
\ldots\end{array}$ & $\begin{array}{l}. . \\
\ddot{*}\end{array}$ & $\begin{array}{l}\cdots \\
\ddot{*}\end{array}$ & $\begin{array}{l}. . \\
\cdots \\
\cdots\end{array}$ & $\begin{array}{r}212 \\
175 \\
37\end{array}$ & $\begin{array}{l}(63) \\
(52) \\
(1 \mathrm{I})\end{array}$ & $\begin{array}{l}64 \\
44 \\
20\end{array}$ & $\begin{array}{l}(56) \\
(39) \\
(17)\end{array}$ & $\begin{array}{r}148 \\
131 \\
17\end{array}$ & $\begin{array}{r}(66) \\
(59) \\
(8)\end{array}$ \\
\hline $\begin{array}{l}\text { Functional psychosis .. } \\
\text { Manic depressive psych } \\
\text { Reactive depressive psy } \\
\text { Other affective psychos } \\
\text { Schizophrenia .. } \\
\text { Paranoid psychosis }\end{array}$ & $\begin{array}{l}\text { osis } \\
\text { chosis } \\
\text { es } \\
. \\
.\end{array}$ & $\begin{array}{l}\cdots \\
\because \\
\cdots \\
\cdots \\
\cdots \\
\cdots\end{array}$ & $\begin{array}{l}\ldots \\
\cdots \\
\cdots \\
\cdots \\
\cdots\end{array}$ & $\begin{array}{l}\cdots \\
\cdots \\
\cdots \\
\cdots \\
\cdots\end{array}$ & $\begin{array}{r}42 \\
17 \\
14 \\
3 \\
7 \\
1\end{array}$ & $\begin{array}{r}(12) \\
(5) \\
(4) \\
(1) \\
(2) \\
(<1)\end{array}$ & $\begin{array}{r}16 \\
6 \\
4 \\
1 \\
4 \\
1\end{array}$ & $\begin{array}{r}(14) \\
(5) \\
(3) \\
(1) \\
(3) \\
(1)\end{array}$ & $\begin{array}{r}26 \\
11 \\
10 \\
2 \\
3 \\
-\end{array}$ & $\begin{array}{r}(11) \\
(5) \\
(4) \\
(1) \\
(1) \\
(-)\end{array}$ \\
\hline $\begin{array}{l}\text { Organic psychosis } \\
\text { Dementia ... } \\
\text { Alcoholic psychosis } \\
\text { Associated with endocri }\end{array}$ & $\begin{array}{l}\ddot{ } \\
\ddot{0} \\
\text { ine disor }\end{array}$ & $\begin{array}{l}\ddot{x} \\
\ddot{r d e r}\end{array}$ & $\begin{array}{l}\cdots \\
\cdots \\
\cdots \\
\cdots\end{array}$ & $\begin{array}{l}\cdots \\
\cdots \\
\cdots \\
\cdots\end{array}$ & $\begin{array}{r}32 \\
2 \\
28 \\
2\end{array}$ & $\begin{array}{r}(10) \\
(1) \\
(8) \\
(1)\end{array}$ & $\begin{array}{r}19 \\
1 \\
18 \\
-\end{array}$ & $\begin{array}{l}(17) \\
(1) \\
(16) \\
(-)\end{array}$ & $\begin{array}{r}13 \\
1 \\
10 \\
2\end{array}$ & $\begin{array}{r}(6) \\
(<1) \\
(5) \\
(1)\end{array}$ \\
\hline $\begin{array}{l}\text { Alcohol abuse . } \\
\text { Alcohol addiction } \\
\text { Heavy drinking (habit }\end{array}$ & al or ep & $\begin{array}{l}. . \\
\text { isodic) }\end{array}$ & $\begin{array}{l}\cdots \\
\cdots \\
\cdots\end{array}$ & $\begin{array}{l}\cdots \\
\because . \\
\cdots\end{array}$ & $\begin{array}{l}61 \\
35 \\
26\end{array}$ & $\begin{array}{r}(18) \\
(10) \\
(8)\end{array}$ & $\begin{array}{l}41 \\
23 \\
18\end{array}$ & $\begin{array}{l}(36) \\
(20) \\
(16)\end{array}$ & $\begin{array}{r}20 \\
12 \\
8\end{array}$ & $\begin{array}{l}(9) \\
(5) \\
(4)\end{array}$ \\
\hline
\end{tabular}


BY H. GETHIN MORGAN, CHRISTOPHER J. BURNS-COX, HELEN POCOCK AND SUSAN POTTLE 569

(29 per cent) and alcohol abuse ( 8 per cent). The last category included patients with clear evidence of addiction as well as those who admitted that they had been drinking heavily in a habitual or episodic way. The incidence of alcohol addiction was ro per cent as judged by the psychiatrists' clinical assessment, and this corresponded closely to the finding of 13 per cent in our questionnaire administered independently by the research team. Functional psychoses were found in only 12 per cent, usually depressive in nature ( 9 per cent) and less commonly schizophrenic ( 2 per cent).

Middlesex Hospital Questionnaire (MHQ): Although the majority of patients (66 per cent) completed the questionnaire, some problems were experienced in the remainder. These were largely due to failure to comprehend certain questions or to fatigue on the part of the patient ( 13 per cent), or to administrative difficulties related to the short stay in hospital (18 per cent). Only 2 per cent refused to cooperate. The scores for patients in our series resemble those of psychiatric out-patients and greatly exceed those of normals, especially for depression and anxiety. The results of the MHQ were found to be consistent when cross-checked with the items from our interview questionnaire. High scores on the MHQ scales for anxiety, depression or obsessionality were associated at a high level ( $\chi^{2}$ tests, $\mathrm{p}<0.00 \mathrm{r}$ ) with previous self-harm and with visiting a general practitioner for 'nerves'. Similarly, high somatic anxiety scores were found in those patients who had visited their G.P. for physical illness.

Health record: Table IV illustrates the way in which the patients had previously been in contact with medical services. Sixty-one per cent had consulted their G.P. at some time in the past year because of 'nerves'; 44 per cent had at some time received psychiatric outpatient treatment and 36 per cent had been psychiatric in-patients. Forty-eight per cent of the patients had at some time previously harmed themselves, almost half of these within a year of the present act.

Use of drugs: In the preceding year prescribed drugs had been taken by 90 per cent of the patients, most commonly hypnotics, tranquillizers and/or antidepressants. Twelve per cent had taken cannabis, 6 per cent LSD, and I per cent opiates. Information concerning alcohol intake over the previous three months, based on our interviews with patients and the hospital notes (Table V), revealed that most patients drank socially without admitting problems as a result. However, alcohol intake had increased significantly over this period in 10 per cent and was accepted as causing problems by a further 13 per cent. When female patients in central areas of the city, where self-harm rates are highest, were compared with those from the remainder, significantly more were found to have alcohol problems ( 28 per cent compared

\section{Table IV}

Previous contact with medical services ( $\%$ of interviewed patients in brackets)

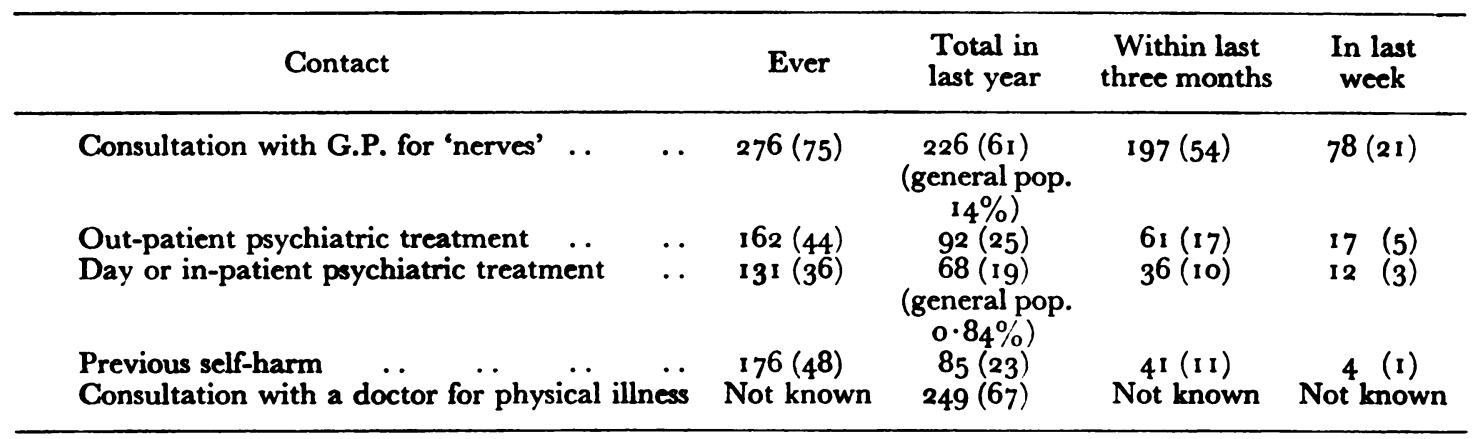


570 DELIBERATE SELF-HARM: GLINICAL AND SOGIO-ECONOMIC CHARACTERISTICS OF 368 PATIENTS

TABle V

Pattern of alcohol intake in previous three months

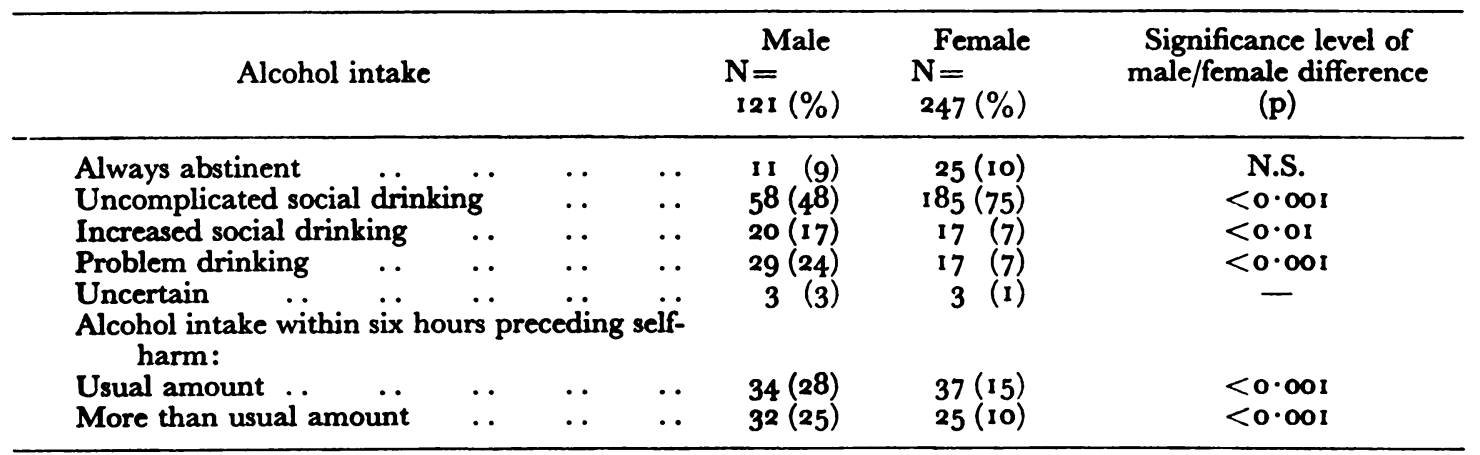

with ro per cent elsewhere, $\left.\chi^{2}=9 \cdot 0, p<0 \cdot 01\right)$. This finding did not apply to male patients who however, were far fewer in number.

Family and personal history: The findings are summarized in Table VI. Twenty-nine per cent of patients with children had needed to seek help from a child guidance clinic or the social services, or had a child in trouble with the police. Separation from a parent was defined as continuous separation for six months or more. Before the age of ten years 22 per cent of patients had been thus separated from their father and 15 per cent from their mother. Physical violence from an adult, sufficient to cause bruising, had been experienced by 20 per cent of the patients some time during childhood.

Antisocial behaviour had been more common in males, whether measured by the incidence of probation or court proceedings before the age of

TABLe VI

Personal history

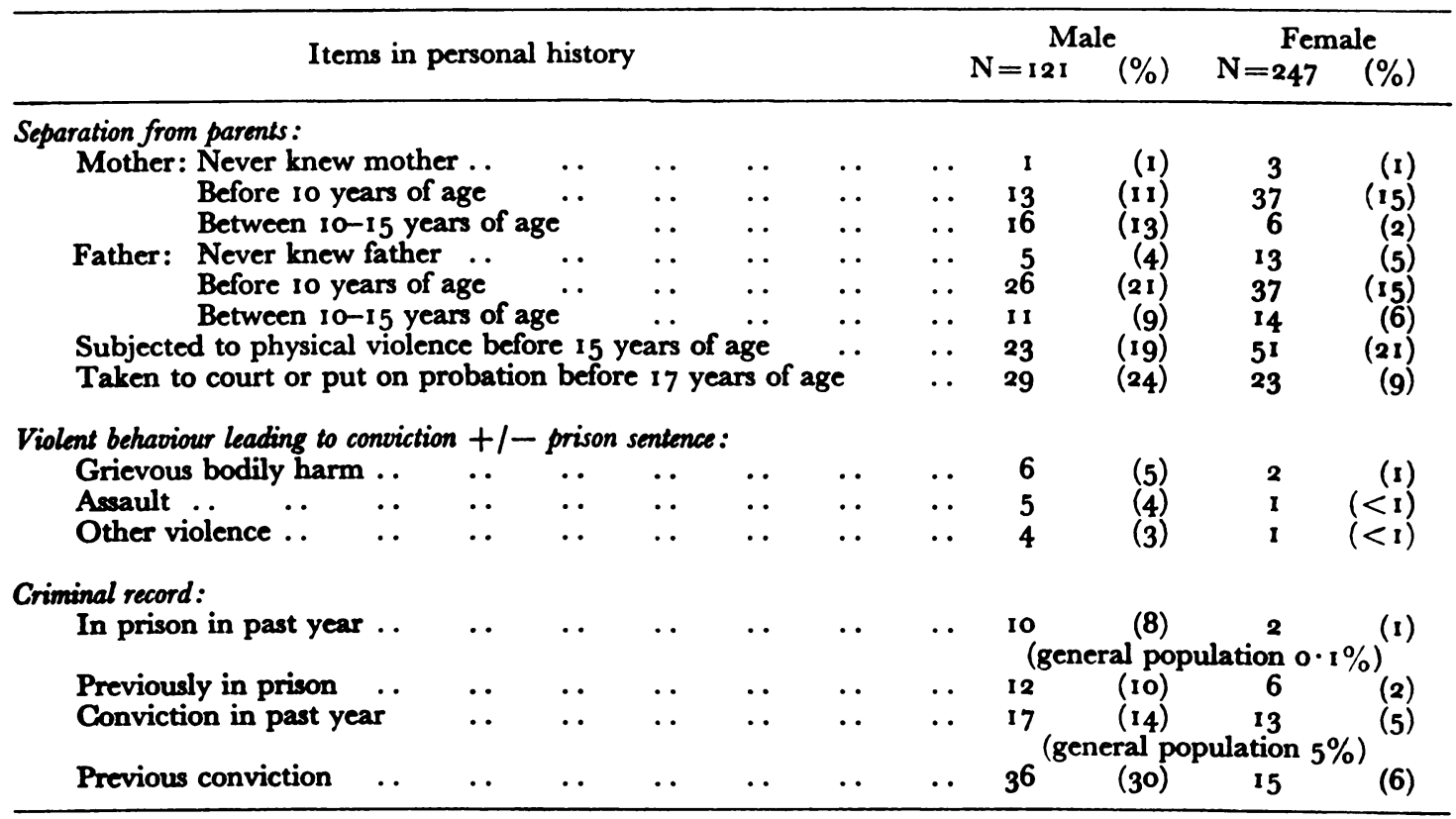


BY H. GETHIN MORGAN, CHRISTOPHER J. BURNS-COX, HELEN POCOCK AND SUSAN POTTLE 57 I

17 years, history of imprisonment or some kind of previous conviction, excluding parking offences. Conviction and/or imprisonment had occurred in the series more often than would have been expected in the general population (Table VI).

Accommodation and social situation: Most patients lived in Bristol ( 83 per cent), though a minority came from surrounding districts ( 16 per cent) or elsewhere (I per cent). Forty-one per cent had been at their present address for less than one year. Seven per cent lived in overcrowded conditions, at a density of 1.5 persons or more per room (city average $I$ per cent). Ten per cent lived alone (city average 8 per cent for those below pensionable age), 9 per cent were in bedsitters or lodgings and 5 per cent in hostels or of no fixed abode. Forty-five per cent regarded themselves as not having a close friend, defined as someone with whom they could discuss personal problems, and 35 per cent felt lonely at all times. Relatives, apart from those with whom they lived, were seen at least once in three months by 75 per cent. Although 75 per cent expressed some kind of religious belief, only 26 per cent had attended a place of worship in the preceding six months.

We have already found that during the period of this study deliberate self-harm was much commoner in the crowded central areas of Bristol than in the suburbs (Morgan et al., 1975). The series was examined further in the light of these findings (Table VII). Patients from central high-rate areas, compared with those from the remainder of the city, were younger and more likely to be overcrowded and to live in bedsitters. They were also more likely to be living away from relatives and to have been at their present address for less than six months.

Ethnic group: The majority of the series $(98$ per cent) were European, and other ethnic groups occurred in the same proportions as in the total city population, according to the 1971 Census data. Most of the patients (92 per cent) had always lived in the United Kingdom.

Social class (Table I): Although the patients were distributed throughout social classes I-V, there was a greater than average number, particularly of men, in social classes IV and V, when compared with the city population assessed by the 1966 Census (ro per cent sample).

Unemployment and financial difficulties: Many patients had employment problems; 36 per cent of the men and 26 per cent of the women were currently unemployed. (Housewives were not included in this category unless they were actively seeking other work.) The national average of persons registered unemployed in 1972 was 4 per cent of employees (Central Statistical Office, 1974); the corresponding figure in our series, with reference only to those who had been unemployed for six months or longer during the preceding year, is 19 per cent. Sickness and lack of available work were the most common reasons given for unemployment. Many patients had also changed their job frequently: of the 60 per cent who had been employed at some time during the preceding

Table VII

Characteristics of interviewed patients from central 'high rate' areas compared with those from remainder of city

\begin{tabular}{|c|c|c|c|c|c|}
\hline Characteristics & & & $\begin{array}{c}\text { Patients } \\
\text { from central } \\
\text { areas } \\
\mathrm{N}= \\
67(\%)\end{array}$ & $\begin{array}{l}\text { Patients } \\
\text { from rest } \\
\text { of city } \\
N= \\
301(\%)\end{array}$ & $\begin{array}{l}\text { Significance level of } \\
\text { male/female differ ence } \\
\text { (p) }\end{array}$ \\
\hline $\begin{array}{l}\text { Below age } 35 \quad \ldots \\
\text { In bedsitters } \quad \ldots \\
\text { At present address less than s } \\
\text { Living away from relatives } \\
\text { Overcrowded conditions }\end{array}$ & 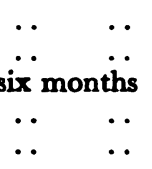 & $\begin{array}{l}\cdots \\
\cdots \\
\cdots \\
\cdots\end{array}$ & $\begin{array}{l}55(82) \\
14(21) \\
32(48) \\
32(48) \\
9(13)\end{array}$ & $\begin{array}{l}188(62) \\
12(4) \\
64(21) \\
81(27) \\
16(5)\end{array}$ & $\begin{array}{l}<0.01 \\
<0.001 \\
<0.001 \\
<0.01 \\
<0.05\end{array}$ \\
\hline
\end{tabular}




\section{DELIBERATE SELF-HARM: GLINICAL AND SOCIO-ECONOMIC CHARACTERISTICS OF 368 PATIENTS}

year, about one third had worked for more than one employer. Sixty-five per cent of those who had been in employment had enjoyed their job, and 53 per cent of housewives had been contented with their role. Some kind of financial diffculties had been experienced by 62 per cent during the preceding year, debts having been incurred by 28 per cent.

\section{Patients not interviewed (102)}

During the study period, 102 self-harm patients attended the Accident and Emergency Department but were not subsequently interviewed by a member of the research team. There were several reasons for this, e.g. 64 patients left the hospital too quickly, I 3 refused interview, 3 were too distressed or ill, 12 were not traced, ro were not interviewed for other reasons (e.g. left hospital in police custody). The 'not interviewed' group was compared with the interviewed series $(368)$ so far as the limited information regarding the former permitted. It was found that 'not interviewed' patients were more likely to have lacerated themselves ( 17 per cent compared with 4 per cent, $\left.x^{2}=19.56, p<0.001\right)$, but had used prescribed drugs less commonly (5I per cent compared with 78 per cent, $\chi^{2}=28 \cdot 8$, $\mathrm{p}<0.001$ ), tending more often to use nonprescribed analgesics. They were also more likely to be 20-25 years of age (33 per cent compared with 20 per cent, $x^{2}=7 \cdot 02$, $\mathrm{p}<\mathrm{o} \cdot \mathrm{or})$ and to be female.

The 'not interviewed' group had either been admitted to a hospital ward after being seen in the Accident Department (47) or discharged directly home (55). Intra-group analysis revealed that the former group resembled very closely the interviewed series, whereas those not admitted appeared to account for the differences already described. The interviewed series was therefore probably representative of 88 per cent of all self-harm cases attending the Accident Department. Follow-up data have subsequently been collected for all these groups.

\section{Discussion}

During the last few decades studies of patients admitted to hospital have shown consistent changes in the pattern of methods used in non-fatal deliberate self-harm. Kessel (1965) demonstrated the diminishing importance since the r 93 os of non-drug poisons such as Lysol and other corrosives: in contrast, up to the early 1960 se use of barbiturates ( 55 per cent), aspirin (12 per cent) and other drugs (mainly the psychotropics-23 per cent) had gradually increased in incidence and coal gas was used in only a small minority ( 9 per cent). He considered that the mounting use of psychotropic drugs was a most important new development and needed to be watched carefully. Our findings, ten years later, show that 95 per cent of self-harm cases involved some form of drug overdosage, and barbiturates have become less important, though hypnotics continue to constitute the most common type of drug and salicylates have increased further. It is clear that the trend towards the increased use of psychotropic drugs in self-harm has continued as predicted by Kessel. These trends are also consistent with the findings of Smith and Davison (1971) in Newcastle in the mid rg6os. The major drug groups used in self-harm were clearly age-related in their frequency, and presumably these findings reflect the types of drugs prescribed or available to different age groups. This has important implications for clinical management after self-harm, particularly when the precise nature of the drug used is not immediately apparent.

Enquiry into the circumstances of the acts of self-harm and the motivation described by our patients revealed that only a minority had made serious plans to prepare for death, tried to avoid discovery, or subsequently regretted not having killed themselves. On the whole, however, the acts of self-harm did not appear to be trivial events, especially for men. A substantial number actively wanted to die at the time, lost consciousness, or required more than conservative resuscitatory measures. These are salutary findings, especially for those who tend to dismiss the danger of self-harming behaviour, and they emphasize the need for careful clinical management in each case.

Psychiatric findings in our series resemble those reported in other cities. The most common categories are reactive depression and personality disorder. The assessment using the 
Middlesex Hospital Questionnaire also emphasized the high level of anxiety and depression in these patients. Birtchnell and Alarcon (1971) have also made this point by demonstrating that 'attempted suicide' patients seen in an Aberdeen Casualty Department scored similarly to a sample of depressed patients on a modified Zung rating scale for depression. Similar findings have also been reported by Silver et al. (1971). Although only a minority of patients in our series had psychotic symptoms they were sufficiently common to emphasize the need for careful psychiatric assessment in all cases. As in other studies of deliberate self-harm, it is clear that alcohol addiction is common (10 per cent) and considerably exceeds the incidence of this problem in the general population estimated recently by Wilkins (1972) as I per cent heavy drinking and 2 per cent alcohol addiction. More than one third of the present series had taken alcohol in the six hours preceding the act of self-harm. Our findings suggest that both the chronic disruption inherent in alcohol addiction and the immediate effects of alcohol intake are important in selfharm and are sufficiently common to make routine search for them imperative, especially in men.

There has been much discussion by other authors regarding the difficulty of categorizing self-harm patients using a conventional psychiatric classification. In our study, the diagnosis of depression in some form was made in a high proportion of patients (6I per cent). The diagnostic category 'depressive neurosis' as defined in the Glossary of Mental Disorders (General Register Office, 1968) was considered appropriate for 53 per cent. Kessel (1965) has warned against the too liberal adoption of psychiatric diagnosis in self-poisoning patients, especially when they do not show significant psychiatric symptoms after physical recovery. He comments that 'distress drives people to self-poisoning acts, and distress is not the exclusive province of the mentally ill', and in his series he judged 26 per cent of males and 20 per cent of females to be free from mental illness, compared with our estimate of 5 per cent and 12 per cent respectively. Other authors have tried to avoid conventional psychiatric labels by adopting such terms as 'acute situational maladjustment or reaction' (Smith and Davison, 1971; Harrington and Cross, 1969), or 'unstable adolescent crisis' (Whitlock and Schapira, 1967). It is our impression that there is a distinct tendency to see the self-harming patient in pejorative terms, of which the stereotype is that of a histrionic young woman who is making a nuisance of herself and who merely needs to pull herself together, preferably without psychiatric intervention. This view does not conform to the high degree of psychological distress which we have found. In such circumstances there seems little to be gained by studiously avoiding a psychiatric diagnosis; hence in our series a diagnosis of depressive neurosis (reactive depression) was used whenever the act of selfharm had occurred in the context of demonstrable anteceding depressive symptoms.

The majority of patients had already sought help for psychiatric problems, over a third having received in-patient care. Almost half had harmed themselves on one or more previous occasions. In the preceding year they had consulted their general practitioners for 'nerves' four times as often as the general population (Shepherd et al., I966). The majority had been given drugs on prescription, usually tranquillizers, antidepressants and/or sedatives, which they had subsequently used for the purpose of self-harm: some had used another person's prescription in this way. In view of these facts it seems that the time has come to review the clinical use of psychotropic drugs, especially for young adults with interpersonal or environmental difficulties. We do not know the rate of overdose per number of psychotropic drug prescriptions, and this needs to be established as an essential part of their evaluation. While undoubtedly they can be invaluable in certain clinical situations, perhaps we should become more discriminating in their use if the problem of deliberate self-harm is to be controlled.

The considerable number of social problems experienced by self-harming patients has been described by other authors (McCulloch and Philip, 1967). Our investigations verify this general picture, showing a combination of social and interpersonal difficulties. These 


\section{DELIBERATE SELF-HARM: GLINICAL AND SOCIO-ECONOMIC CHARACTERISTICS OF 368 PATIENTS}

findings, together with the fact that deliberate self-harm has a much greater incidence in the central urban area, have clear implications for the location and emphasis of health care services.

\section{AckNowLedGements}

Financial support for this study was provided by the Medical Research Council and the research was carried out at the Department of Mental Health, University of Bristol. We are grateful to Professor D. Russell Davis, Dr. N. Kreitman and Dr. P. Sainsbury for helpful discussions. Our thanks are also due to the staff of the Bristol Royal Infirmary and to the Medical Research Division of the Health Education Council for their cooperation, to Mrs. N. Iles for secretarial assistance, to Miss E. Duncan, Mrs. A. Morris and Mrs. J. Williams of the Department of Public Health, University of Bristol for processing our data, and to Miss J. Barton for statistical analysis.

\section{RETERENCES}

Artiken, R. C. B., Buglass, D. \& Kremtman, N. (1969) The changing pattern of attempted suicide in Edinburgh, 1962-67. British Fournal of Preventive and Social Medicine, 23, 111 1-15.

Aldzrson, M. R. (1974) Self-poisoning-what is the future? Lancet, $i$, 1040-3.

Birtchnell, J. \& Alarcon, J. (1971) Depression and attempted suicide. British Foumal of Psychiatry, 118, $289-96$.

Census (1966) Census of Population Reports, 10\% sample (England and Wales).

- (1971) Census of Population Reports (England and Wales).

Central Statistical Opfice (1974) Social Trends, 5. London: H.M.S.O.

CRrsp, A. H. \& PRIrst, R. G. (1971) Psychoneurotic profiles in middle age. A study of persons aged 40 to 65 registered with a general practitioner. British Joumal of Psychiatry, 119, 385-92.
Grown, S. \& Crisp, A. H. (1966) A short clinical diagnostic self-rating scale for psychoneurotic patients. British Fournal of Psychiatry, 112, 91 7-23.

General Register Opfice (1968) A Glossaty of Mental Disorders. London.

Harrington, J. \& Cross, K. (1969) Cases of attempted suicide admitted to a general hospital. British Medical Journal, ii, 1352-5.

Kesser, N. (1965) Self-poisoning-part I. British Medical Joumal, ii, 1265-70.

McCulloch, J. W. \& Phurp, A. E. (1967) Social variables in attempted suicide. Acta Psychiatrica Scandinavica, 43, $341-6$.

Morgan, H. G., Pocock, H. \& Pottle, S. (1975) The urban distribution of non-fatal deliberate self-harm. British Fournal of Psychiatry 126, 319-28.

Shepherd, M., Cooper, B., Brown, A. C. \& Kalton, G. W. (1966) Psychiatric Illness in General Practice. London: Oxford University Press.

Silver, M. A., Bohnert, M., Bzck, A. T. \& Marcus, D. (1971) Relation of depression of attempted suicide and seriousness of intent. Archives of General Psychiatry, $25,573-6$.

Surtr, J. S. \& DAvison, K. (1971) Changes in the pattern of admissions for attempted suicide in Newcastle-upon-Tyne during the 1960s. British Medical foumal, 4o 412-15.

Wrissman, M. M. (1974) The epidemiology of suicide attempts, 1960 to 1971. Archives of General Psychiaty, 30, 737-46.

WhITLOCK, F. \& SchapiRA, K. (1967) Attempted suicide in Newcastle-upon-Tyne. British Joumal of Psychiatry, I13, 423-34.

Wrukns, R. H. (1972) The use of a questionnaire to detect an alcoholic in general practice. Paper presented to the International Workshop on Family Medicine, Tel Aviv.

H. Gethin Morgan, M.A., M.D., M.R.C.P., M.R.C.Psych., D.P.M., Consultant Senior Lecturer, Department of Mental Health, University of Bristol, 39/4I, St. Michael's Hill, Bristol BS2 8DZ; Honorary Consultant Psychiatrist, Avon Area Health Authority

Christopher J. Burns-Cox, M.D., M.R.C.P., Consultant Physician, Frenchay Hospital, Bristol

Helen Pocock, B.A., Research Assistant, Department of Mental Health, University of Bristol

Susan Pottle, M.A., Research Assistant, Department of Mental Health, University of Bristol

(Received I7 February, 1975) 